\title{
Rancang Bangun Edugame sebagai Upaya Peningkatan Safety Awareness Penumpang terhadap on Board Behaviour and Carried
}

\author{
Things
}

Wiguna Wisbang Puritano, dan Sudiarno Adithya

Departemen Teknik Industri, Fakultas Teknologi Industri, Institut Teknologi Sepuluh Nopember (ITS)

Kampus ITS Sukolilo-Surabaya 60111, Indonesia

adithya.sudiarno@gmail.com

\begin{abstract}
Abstrak - Pertumbuhan minat masyarakat dalam menggunakan jasa transportasi udara yakni pesawat sebagai akses untuk mempermudah pekerjaan maupun berlibur menjadi fokus pada penelitian ini. Aspek keselamatan dan keamanan menjadi aspek utama yang perlu diperhatikan oleh penumpang sebelum memutuskan untuk menggunakan pesawat. Aspek keamanan berupa peraturan barang bawaan penumpang menjadi tanggungjawab aviation security sedangkan peraturan perilaku penumpang dijelaskan oleh pramugari dalam bentuk safety induction sebelum take-off. Materi edukasi mengenai keselamatan dan keamanan penumpang pesawat ditampilkan dalam betuk game (Edugame) yang berjudul Airport Guardian. Penyampaian edukasi melalui Edugame Airport Guardian ini cukup efektif sebagai sebuah tool pemahaman masyarakat. Efektivitas ini dapat diuji melalui metode pengujian "Pre and post test". Hasil dari pengujian ini juga menunjukkan bahwa terdapat perbedaan yang signifikan antara pengujian sebelum dan sesudah mencoba game Airport Guardian. Parameter keberhasilan sebuah game yang dibangun dapat ditentukan dari tingkat usabilitas game tersebut. Edugame Airport Guardian telah memenuhi variabel usabilitas learnability, efficiency, memorability, errors yang didapatkan dari hasil kuesioner umum dan variabel satisfaction melalui kuesioner System Usability Scale (S US). Standar kepuasan pengguna dapat terpenuhi setelah dilakukan beberapa perbaikan pada game. Perbaikan pada game dilakukan berdasarkan tanggapan pengguna saat usability testing.
\end{abstract}

Kata Kunci-Safety Induction, Edugame, Usability Testing, Variabel Usabilitas, Kuesioner System Usability Scale.

\section{PENDAHULUAN}

$\mathrm{P}$ ENINGKATAN minat penduduk Indonesia untuk berlibur maupun kepentingan pekerjaan telah berpengaruh langsung pada pertumbuhan jumlah pengguna jasa transportasi umum. Hal ini juga berlaku pada jenis transportasiudara, salah satunya pesawat terbang yang kini semakin diminati masyarakat khususnya dalam melakukan perjalanan jauh. Pertumbuhan minat penduduk Indonesia terhadap moda transportasi pesawat ini telah didukung oleh bertambahnya jumlah maskapai penerbangan. Berbagai jenis media informasi telah digunakan oleh maskapai penerbangan demi mendapatkan kepercayaan customer agar tertarik untuk menggunakan jasanya. Berikut ini merupakan gambaran pertumbuhan jumlah penumpang pada bandara Soekarno-Hatta.

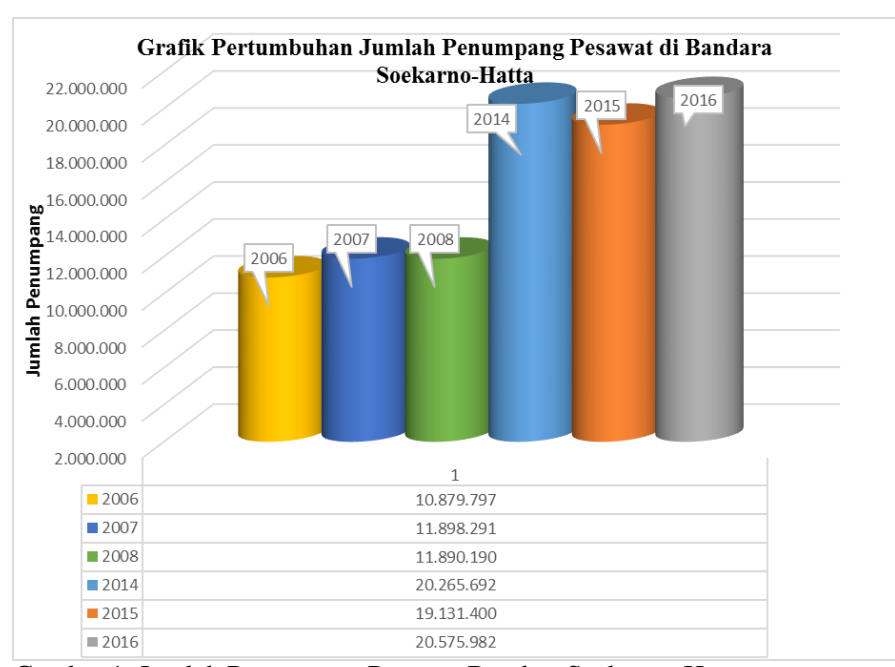

Gambar 1. Jumlah Penumpang Pesawat Bandara Soekarno-Hatta Sumber: Badan Pusat Statistik

Jika melihat pada tahun 2006 hingga 2008 ini jumlah penumpang masih jauh lebih sedikit dibandingkan tiga tahun terakhir dikarenakan pada periode tersebut belum terjadi pertumbuhan ekonomi yang pesat sehingga harga pesawat dinilai masih cukup mahal, serta rute yang ditawarkan juga belum cukup banyak. Pertumbuhan jumlah penumpang selama kurun waktu tiga tahun terakhir ini sempat mengalami penurunan sekitar 1 juta penumpang pada tahun 2015. Menurut pernyataan Badan Pusat Statistik (BPS), hal ini dikarenakan isu kecelakaan pesawat dan maraknya pilot yang menyalahgunakan narkoba. Namun hal ini dapat kembali normal pada tahun berikutnya. Jumlah penumpang di Bandara Soekarno-Hatta pada tahun 2016 berada pada angka 20.575.982 penumpang. Peningkatan jumlah penumpang ini sejalan dengan pertumbuhan ekonomi Indonesia dan juga peningkatan pendapatan per kapita penduduk Indonesia. Namun demikian, pertumbuhan ini tidak terlepas dari peristiwa kecelakaan.

Berdasarkan investigasi Komite Nasional Kecelakaan Transportasi (KNKT) pada Media Release KNKT tahun 2016 untuk Data Investigasi Kecelakaan Penerbangan tahun 20102016, penyebab kecelakan pesawat terbesar secara berurutan didominasi oleh faktor human error, masalah teknis, kemudian faktor lingkungan (cuaca dan lainnya) [1]. Pernyataan ini juga didukung melalui Helmreich dan Foushe (dalam Krivonos, 
2007) yang menyatakan dalam penelitiannya bahwa penyebab kecelakaan pesawat terbesar yakni faktor human error yang berkontribusi sekitar 70\% [2]. Human error yang dimaksud pada kecelakaan pesawat terbang ini ditujukan kepada beberapa pihak seperti kepada pilot, pegawai Air Traffic Controller [3]. Kendati demikian, penumpang masih memiliki probabilitas sebagai penyebab kecelakaan, sebagai contohnya pada tahun 2000 diketahui pesawat Crossair dengan nomor penerbangan LX 498 menukik dan jatuh serta menewaskan 10 penumpang. Kecelakaan ini disebabkan oleh HP yang menyala dan kemudian mengalami gangguan kemudi (Lestari, 2013) [4]. Peristiwa kecelakaan ini berindikasi bahwa penumpang tetap memiliki tanggungjawab untuk selalu berhati-hati ketika berencana menggunakan pesawat sebagai alat transportasinya.

Aspek keselamatan penumpang pesawat ini selalu diingatkan oleh aviation security yang terkait dengan barang bawaan penumpang dan pramugari dalam hal peraturan perilaku penumpang saat berada di pesawat. Kedua hal ini penting untuk diperhatikan penumpang saat hendak menggunakan pesawat karena dapat berpotensi untuk mengganggu proses penerbangan. Peraturan terkait barang bawaan serta perilaku penumpang di dalam pesawat telah tercantum pada website resmi beberapa maskapai penerbangan. Berdasarkan hasil wawancara dengan pilot dan pramugari pada maskapai penerbangan berbeda didapatkan bahwa masih cukup sering ditemukan penumpang yang tidak taat pada peraturan yang berlaku, namun terdapat juga yang belum mengetahui peraturan tersebut. Sebagian besar penumpang tidak mengetahui secara pasti mengenai risiko yang ditimbulkan jika peraturan tersebut dilanggar. Perlu adanya metode inovatif yang dapat memberikan pengetahuan serta meningkatkan kesadaran masyarakat akan pentingnya memahami aspek keselamatan sebagai penumpang pesawat.

Melihat kondisi terkini pada industri penerbangan di Indonesia khususnya dan berdasarkan pengalaman pramugari pada maskapai penerbangan di Indonesia, maka hal ini sejalan dengan tujuan penelitian ini. Penelitian ini bertujuan untuk memberikan edukasi kepada seluruh masyarakat agar memiliki kesadaran penuh atas pentingnya keselamatan selama berpergian menggunakan pesawat yang dikemas dalam bentuk edugame. Edugame yang dibangun harus memenuhi keinginan dan kebutuhan konsumen sebagai pengguna game serta dapat menjadi tools pemahaman mengenai aspek keselamatan penumpang pesawat.

\section{METODOLOGI PENELITIAN}

\section{A. Tahap Studi Literatur}

Tahap Studi Literatur dilakukan untuk mengetahui informasi apa saja yang dibutuhkan dan sesuai dengan penelitian ini. Perhatian utama pada tahap ini adalah melakukan identifikasi mengenai aspek keamanan dan keselamatan pada penumpang pesawat.

\section{B. Tahap Pengumpulan Data}

Pada Tahap Pengumpulan Data ini berisi tentang informas i dari narasumber mengenai peraturan perilaku penumpang serta kendala yang dialami ketika memberikan safety induction, informasi tercantum mengenai peraturan barang bawaan penumpang, serta sumber pustaka lain yang berkaitan dengan peraturan tersebut.

\section{Tahap Perancangan Konten Game}

Pada Tahap Perancangan Konten Game ini dilakukan analisis mengenai perancangan sistem edukasi. Pada tahap ini juga dilakukan identifikasi mengenai peraturan perilaku penumpang serta peraturan yang terkait dengan barang bawaan penumpang.

\section{Tahap Pembuatan Game}

Tahap ini adalah tahap eksekusi dari keseluruhan tahap persiapan untuk perancangan game ini. Pembuatan game ini juga harus melalui perancangan matang mengenai jalan cerita (alur main) dari game ini.

\section{E. Tahap Penentuan Variabel Usabilitas}

Pada tahap ini, dilakukan identifikasi variabel apa saja yang dijadikan sebagai parameter pengukuran usability. Pada pembuatan game Airport Guardian ini, variabel usabilitas yang diuji adalah learnability, efficiency, errors, memorability, errors, dan satisfaction.

\section{F. Tahap Pengujian Game}

Tahap pengujian game ini harus melalui dua tahap, yaitu pengujian game oleh pembuat untuk menentukan apakah game yang telah dirancang ini sesuai dengan konsep serta pengujian game kepada pengguna melalui metode pengujian Pre and Post Test dan Usability Testing.

\section{G. Tahap Analisis Perancangan Sistem dan Evaluasi}

Tahap evaluasi ini penting dilakukan untuk membuat game menjadi lebih sesuai dengan konsep yang telah dibuat dan sesuai dengan keinginan dan kebutuhan konsumen sebagai pengguna game ini. Jika belum sesuai maka perlu dilakukan langkah perbaikan baik dari segi jalan cerita game maupun desain tampilan yang diharapkan. Tahap terakhir dilakukan pengambilan kesimpulan terhadap penelitian yang telah dilakukan.

\section{PEMBAHASAN}

\section{A. Pembangunan Game}

Pembangunan game ini merupakan tahap utama yang harus dilakukan pada penelitian ini. Pembangunan game Airport Guardian ini terdiri atas menu gameplay utama yakni menu Seleksi Barang Bawaan dan menu Implementasi Safety Induction. Materi edukasi utama terdapat pada menu Kategori Barang Bawaan serta Peraturan Perilaku Penumpang. Pada menu Kategori Barang Bawaan, pengguna diberikan edukasi mengenai jenis barang apa saja yang termasuk dalam kategori yang hanya boleh diletakkan di dalam bagasi tercatat dengan syarat memberikan laporan kepada petugas check-in bandara serta kategori barang yang dilarang dibawa baik di dalam kabin maupun pada bagasi tercatat. Pada menu Peraturan Perilaku Penumpang terdapat materi edukasi berupa perilaku yang harus dipatuhi penumpang sehingga pada menu ini berisi larangan atau himbauan yang harus dipatuhi dan juga ditampilkan risiko potensial yang diterima jika peraturan tersebut dilanggar. 
Proses pembangunan edugame dapat dijelaskan melalui flowchart dibawah ini.

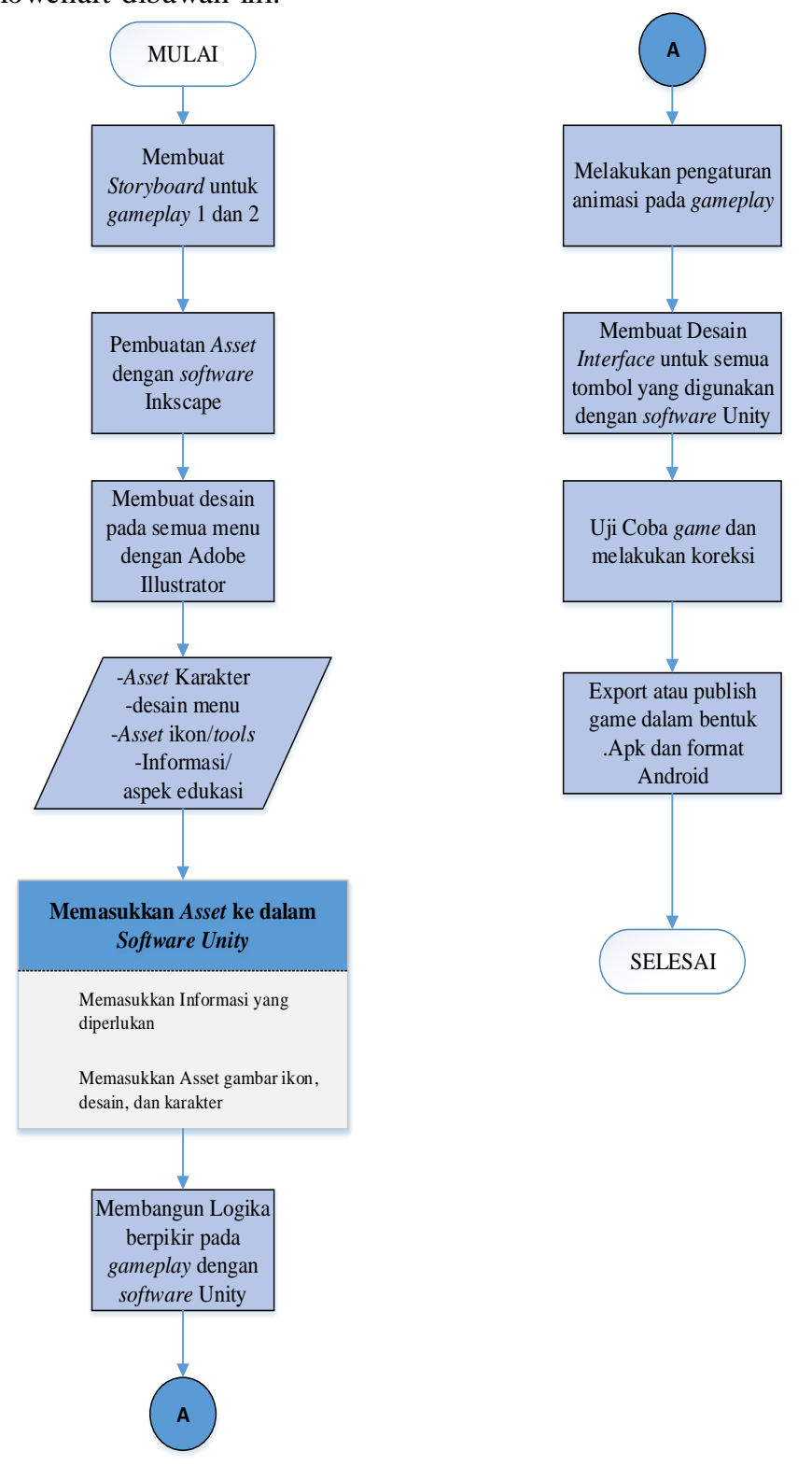

Gambar 2. Proses Pembangunan edugame

\section{B. Metode Pengujian Pre and Post Test}

Metode Pengujian ini berisi beberapa pertanyaan terkait informasi yang ingin disampaikan kepada responden. Pengujian awal atau pre test ini diberikan kepada responden sebelum menggunakan aplikasi sehingga berdasarkan pada website resmi suatu maskapai penerbangan dan kartu petunjuk keselamatan penumpang yang terdapat pada setiap maskapai. Jumlah responden yang melakukan proses pengujian game ini sebanyak 35 responden dengan kategori responden adalah subyek yang sering bepergian, komunitas game, dan subyek di bidang komunikasi. Waktu maksimal yang diberikan kepada setiap responden untuk mempelajari referensi (pre test) dan edugame (post test) serta mengerjakan lembar pengujian adalah 15 menit. Berikut ini hasil rekapitulasi metode pengujian pre and post test menggunakan metode statistik Wilcoxon.

\section{Wilcoxon Signed Ranks Test}

\begin{tabular}{|c|c|c|c|c|}
\hline \multicolumn{5}{|c|}{ Ranks } \\
\hline & & $\mathrm{N}$ & Mean Rank & Sum of Ranks \\
\hline \multirow[t]{4}{*}{ PostTest - PreTest } & Negative Ranks & $0^{\mathrm{a}}$ & .00 & .00 \\
\hline & Positive Ranks & $32^{\circ}$ & 16.50 & 528.00 \\
\hline & Ties & $3^{\mathrm{c}}$ & & \\
\hline & Total & 35 & & \\
\hline
\end{tabular}

a. PostTest $<$ PreTest

b. PostTest $>$ PreTest

c. PostTest $=$ PreTest

Gambar 3. Hasil Pre and Post Test

Test Statistics $^{\mathrm{a}}$

\begin{tabular}{lr} 
& \multicolumn{1}{c}{$\begin{array}{c}\text { PostTest - } \\
\text { PreTest }\end{array}$} \\
\hline$z$ & $-5.064^{\circ}$ \\
\hline Asymp. Sig. (2-tailed) & .000 \\
\hline a. Wilcoxon Signed Ranks Test & \\
b. Based on negative ranks.
\end{tabular}

Gambar 4. Hasil Statistik Pre and Post Test

Berdasarkan hasil pengujian dengan Metode Wilcoxon Signed Ranks Test Menggunakan software SPSS, dapat disimpulkan bahwa nilai rata-rata post test responden lebih baik daripada pre test. Hal ini dapat dilihat pada bagian positive rank yang bernilai 32 dan nilai mean rank adalah 16.5 yang berarti terdapat 32 responden yang memiliki peningkatan rata-rata sebesar 16.5. Pada uji hipotesis ini didapatkan nilai Asymp. Sig. (2-tailed) sebesar 0.000 yang berarti $<0.05$. Berdasarkan nilai tersebut dapat diartikan bahwa terdapat perbedaan yang signifikan antara kedua tahap pengujian sehingga disimpulkan bahwa ada pengaruh penggunaan edugame terhadap pemahaman responden.

\section{Metode Pengujian Usability Testing (Kuesioner SUS)}

Kuesioner usabilitas yang fokus pada variabel satisfaction atau kepuasan pelanggan terhadap game yang dibangun ini dinilai cukup efektif untuk mendapatkan respon khusus berupa aspek kepuasan pengguna. Pada kuesioner SUS ini tidak terjadi modifikasi dikarenakan jenis kuesioner SUS telah memiliki sifat yang robust. Berikut ini merupakan hasil rekapitulasi kuesioner SUS yang telah dinilai oleh responden.

Tabel 1.

Hasil Rekapitulasi Kuesioner SUS

\begin{tabular}{|c|c|c|c|c|c|}
\hline \multicolumn{6}{|c|}{ Satisfaction } \\
\hline No & Kriteria & $\begin{array}{l}\text { Nilai } \\
\text { Modus }\end{array}$ & Poin & $\begin{array}{l}\text { Total } \\
\text { Poin } \\
\text { (A) }\end{array}$ & $\begin{array}{c}\text { Skor } \\
\text { SUS } \\
(A * 2,5)\end{array}$ \\
\hline 1 & Saya merasa akan sering menggunakan game ini & 4 & 3 & \multirow{10}{*}{31} & \multirow{10}{*}{77,5} \\
\hline 2 & Saya rasa game ini terlalu rumit & 2 & 3 & & \\
\hline 3 & Saya rasa game ini mudah untuk digunakan & 5 & 4 & & \\
\hline 4 & $\begin{array}{l}\text { Saya merasa memerlukan bantuan orang lain } \\
\text { untuk mengoperasikan game ini }\end{array}$ & 2 & 3 & & \\
\hline 5 & $\begin{array}{c}\text { Saya rasa fitur dalam game ini sudah terintegrasi } \\
\text { dengan baik }\end{array}$ & 4 & 3 & & \\
\hline 6 & Saya rasa banyak inkonsistensi dalam game ini & 2 & 3 & & \\
\hline 7 & $\begin{array}{l}\text { Saya rasa orang-orang akan belajar } \\
\text { menggunakan game ini secara cepat }\end{array}$ & 4 & 3 & & \\
\hline 8 & Saya rasa game ini sangat sulit untuk digunakan & 2 & 3 & & \\
\hline 9 & $\begin{array}{c}\text { Saya merasa sangat yakin dalam menggunakan } \\
\text { game ini }\end{array}$ & 4 & 3 & & \\
\hline 10 & $\begin{array}{c}\text { Saya perlu banyak belajar sebelum dapat } \\
\text { menggunakan game ini }\end{array}$ & 2 & 3 & & \\
\hline
\end{tabular}


Hasil rekapitulasi kuesioner SUS di atas menunjukkan bahwa nilai SUS adalah sebesar77,5. Tabel di atas adalah tabel perbaikan akhir setelah dilakukan beberapa perubahan pada edugame Airport Guardian. Kotak yang berwarna kuning berarti bahwa terjadi perubahan nilai pada pernyataan tersebut setelah dilakukan pengujian ulang pada beberapa responden yang telah memberikan saran sehingga pengujian ulang ini menjadi langkah evaluasi terhadap feedback yang telah diberikan oleh responden. Berikut ini merupakan parameter penilaian yang digunakan untuk pengambilan kesimpulan pada hasil SUS yang didapatkan.

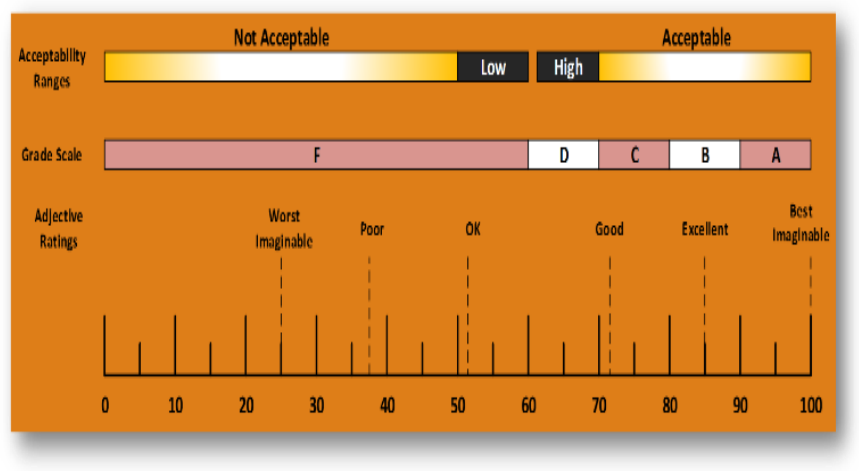

Gambar 5. Parameter Penilaian Kuesioner SUS.

Berdasarkan parameter penilaian di atas, dapat disimpulkan bahwa game Airport Guardian memiliki penilaian "Good" dan dapat diterima "Acceptable" [5]. Penilaian ini didapatkan dari hasil kuesioner SUS setelah dilakukan beberapa perbaikan pada game dan pada pengujian ulang. Dengan demikian dapat disimpulkan bahwa edugame Airport Guardian dapat diterima oleh responden sebagai perwakilan pada usability testing ini.

\section{Metode Pengujian Usability Testing (Kuesioner Umum)}

Kuesioner usabilitas umum yang mencakup semua variabel selain satisfaction. Metode ini dilakukan secara terpisah karena kuesioner SUS dinilai cukup efektif untuk mendapatkan respon khusus berupa aspek kepuas an pengguna sehingga perlu adanya bentuk kuesioner lain yang dapat menangkap respon pengguna pada aspek variabel lain (learnability, efficiency, memorability, errors). Setelah dilakukan rekapitulasi terhadap hasil penilaian responden terhadap pada kuesioner umum, didapatkan hasil sebesar 93\%. Sesuai dengan parameter penilaian, dapat disimpulkan bahwa game Airport Guardian ini sangat baik dan berhasil [6]. Nilai tersebut mengartikan bahwa edugame Airport Guardian telah memenuhi variabel usabilitas learnability, efficiency, memorability, dan errors.

\section{E. Analisis Kekurangan dan Implementasi Perbaikan}

Analisis kekurangan dan rencana perbaikan pada game ini menjelaskan keluhan yang dialami selama proses ujicoba game Airport Guardian serta langkah perbaikan yang dapat dilakukan untuk memperbaiki sistem pada game ini. Meskipun didapatkan hasil yang baik, perlu dilakukan perbaikan pada beberapa permasalahan yang masih terdapat pada game ini agar performansi game semakin baik dan dapat menarik minat pengguna untukmengunduh dan memainkan game ini. Berikut ini merupakan poin-poin kekurangan game serta upaya perbaikan yang dilakukan.
1. Terdapat kesalahan kriteria barang pada menu Seleksi Barang Bawaan. Kesalahan kriteria barang amunisi (semulanya berada pada barang yang sepenuhnya dilarang). Upaya perbaikannya adalah memasukkan amunisi ke dalam kriteria barang yang boleh diletakkan di bagasitercatat.

2. Penempatan menu instruksi ke dalam masing-masing gameplay yang bertujuan untuk memudahkan pemahaman pengguna terhadap task yang harus dijalankan.

\section{KESIMPULAN/RINGKASAN}

Pada penelitian ini dapat diketahui bahwa terdapat beberapa peraturan yang harus dipahami oleh penumpang pesawat. Peraturan yang terfokus pada On Board Behaviourand Carried Things ini didapatkan dari hasil wawancara dengan pilot dan pramugari serta data sekunder resmi lainnya. Pada penelitian ini juga didapatkan kesimpulan bahwa game Airport Guardian telah memenuhi standarusabilitas melalui usability testing yang menggunakan kuesioner SUS dan kuesioner umum. Nilai yang dicapai sebesar 77,5 pada kuesioner SUS dan kuesioner umum sebesar 93\% yang berarti bahwa game ini dapat diterima (acceptable) dan baik (good) [5] serta sangat baik \& berhasil [6]. Edugame Airport Guardian ini juga telah memenuhi persyaratan sebagai tools pemahaman yang lebih baik dari media eksisting sesuai dengan hasil pengujian Pre and Post Test.

Berikut merupakan tampilan Edugame Airport Guardian.

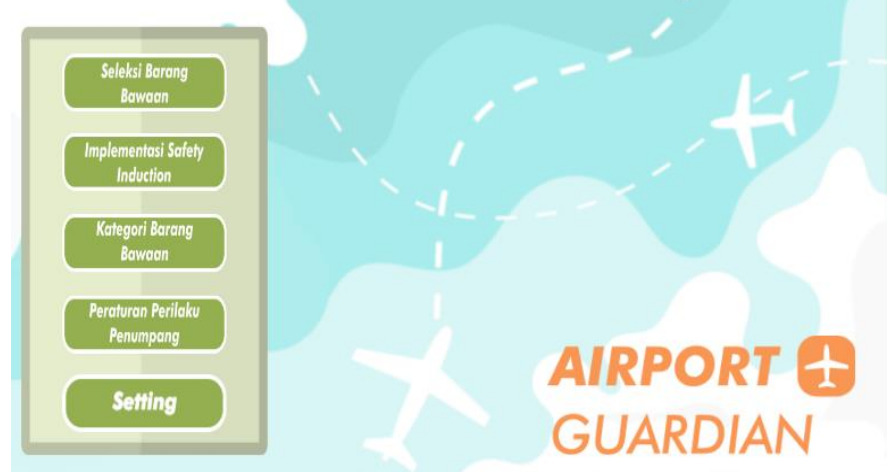

Gambar 6. Tampilan Menu Awal Airport Guardian.

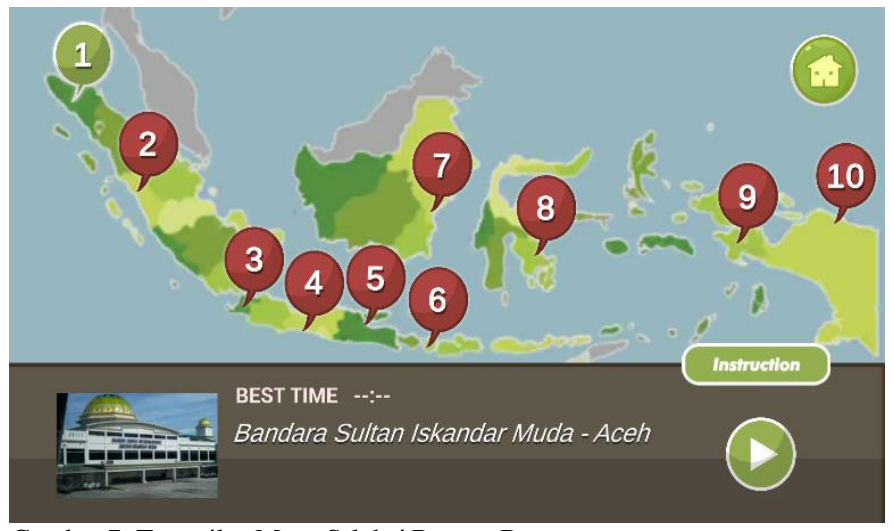

Gambar 7. Tampilan Menu Seleksi Barang Bawaan. 


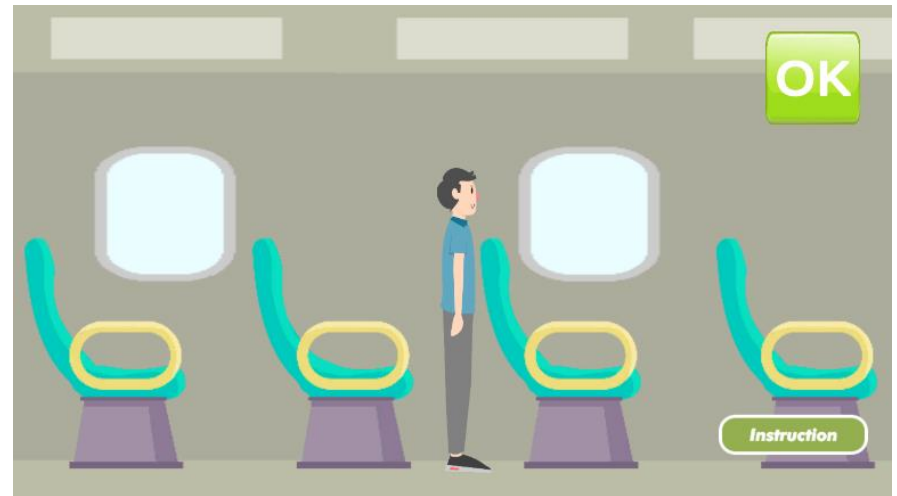

Gambar 8. T ampilan Menu Implementasi Safety Induction.

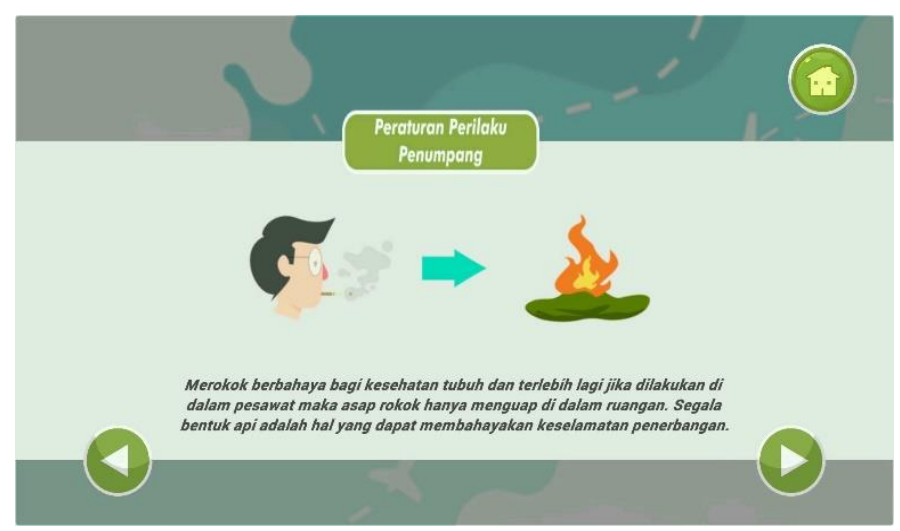

Gambar 9. Tampilan Menu Peraturan Perilaku Penumpang.

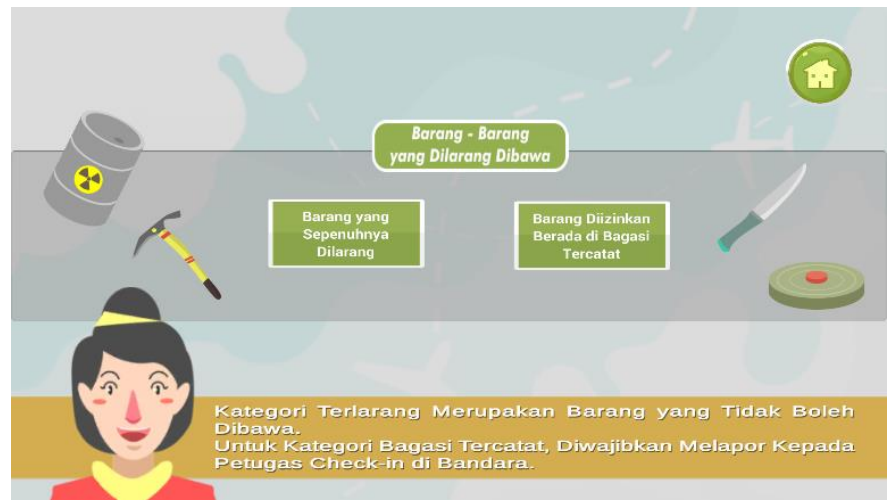

Gambar 10. Tampilan Menu Barang-Barang yang Dilarang Dibawa.

\section{DAFTAR PUSTAKA}

[1] Komite Nasional Keselamatan Transportasi, "Analisis Data Kecelakaan dan Investigasi Transportasi Udara," Jakarta, 2012.

[2] P. D. Krivonos, "Communication in Aviation Safety: Lessons Learned and Lessons Required," in Australia \& New Zealand Societies: Regional Seminar of Air Safety Investigator, 2007.

[3] F. H. Hawkins, Human Factors In Flight, 2nd ed. Aldershot: Avebury Technical, 1995.

[4] M. Lestari, "Cerita Kecelakaan Pesawat Akibat Ponsel Menyala," www.merdeka.com, 2013. .

[5] J. Brooke, "SUS-A Quick and Dirty Usability Scale," Usability Eval. Ind., vol. 189, pp. 4-7, 1986.

[6] S. Arikunto, Prosedur Penelitian Suatu Pendekatan Praktik, Revisi. Jakarta: Rineka Cipta, 2009. 